\title{
PROVAS EPICUTÂNEAS SOB IMUNOSSUPRESSÃO SISTÉMICA - CONTRA-INDICAÇÃO ABSOLUTA?
}

\author{
Ana Brasileiro', Sara Campos', Ana Fidalgo², Lurdes Lobo³ \\ IInterna do Internato Complementar de Dermatologia e Venereologia//Resident of Dermatology and Venereology, Serviço de \\ Dermatologia e Venereologia do Hospital S. António dos Capuchos, Centro Hospitalar Lisboa Central \\ ${ }_{2}^{2}$ Assistente Hospitalar Graduada de Dermatologia/Graduated Consultant of Dermatology and Venereology, Serviço de Dermatologia \\ e Venereologia do Hospital S. António dos Capuchos, Centro Hospitalar Lisboa Central \\ ${ }^{3}$ Chefe de Serviço de Dermatologia/Consultant Chief of Dermatology and Venereology, Serviço de Dermatologia e Venereologia do \\ Hospital S. António dos Capuchos, Centro Hospitalar Lisboa Central \\ Serviço de Dermatologia, Hospital S. António dos Capuchos, Centro Hospitalar Lisboa Central, Lisboa, Portugal
}

RESUMO - Introdução: As provas epicutâneas (PE) são o exame complementar de diagnóstico indicado para avaliação de suspeita de dermite de contacto alérgica. Idealmente, devem ser realizadas sem que o doente se encontre sob imunossupressores. Existem contudo situações clínicas em que tal não é possível, não havendo informação disponível acerca de como realizar e valorizar os resultados das PE nestes doentes. O objectivo do presente trabalho é rever a literatura no que concerne à realização de PE sob imunossupressão iatrogénica. Material e Métodos: Revisão da literatura relevante para o tema publicada até Janeiro de 2015 e indexada à Medline. Resultados: De acordo com o reportado na literatura, foram realizadas PE em 77 doentes sob corticóide sistémico, 78 doentes sob ciclosporina (CyA), 6 sob azatioprina, 10 sob metotrexato (MTX), 4 sob micofenolato de mofetil (MMF), 11 sob fármacos anti-factor de necrose tumoral e 7 sob fármaco anti-IL-12/23. Foram ainda descritos 15 casos de realização de PE sob associação de imunossupressores. Verificaram-se reacções positivas em todos os grupos. Conclusão: $O$ tratamento concomitante com imunossupressores não deve ser uma contra-indicação para realização de PE, estando descritas reaç̧ões positivas em doentes sob prednisolona, azatioprina, CyA, MTX, MMF, infliximab, etanercept, adalimumab e ustecinumab. Os resultados negativos ou duvidosos devem, contudo, ser interpretados de forma cautelosa.

PALAVRAS-CHAVE - Provas epicutâneas, imunossupressores.

\section{PATCH TESTS UNDER SYSTEMIC IMMUNOSSUPRESSION - AN ABSOLUTE CONTRA-INDICATION?}

ABSTRACT - Introduction: Epicutaneous patch tests are the gold standard for the diagnosis of allergic contact dermatitis. Ideally, the tests should be performed without concomitant systemic imunossupression, which is not possible in some clinical situations. There are no guidelines on how to perform the tests or evaluate the results in such cases. We aimed to review the literature concerning patch testing under iatrogenic immunossuppression. Material and methods: Literature review of Medline indexed publications related to the subject until January 2015. Results: According to published data, patch testing was performed in 77 patients under systemic corticosteroid, 78 under cyclosporine (CyA), 6 under azathioprine, 10 under metothrexate (MTX), 4 under mycophenolate mofetil (MMF), 11 under anti tumoral necrosis factor agents and 7 under IL-12/23 inhibitor. Additionaly, 15 patients under association of immunosuppressors also underwent patch testing. Positive reations were observed in all groups. Conclusion: Ongoing treatment with immunossuppressants should not be an absolute contra-indication for patch testing, as positive reactions can be elicited in patients treated with prednisolone, azathioprine, CyA, MTX, MMF, infliximab, etanercept, adalimumab and ustecinumab. Negative or doubtful results should be interpreted with more cautious.

KEY-WORDS - Patch tests, immunosuppressive agentes.

Conflitos de interesse: Os autores declaram não possuir conflitos de interesse. No conflicts of interest.

Suporte financeiro: O presente trabalho não foi suportado por nenhum subsídio ou bolsa. No sponsorship or scholarship granted. Recebido/Received - Janeiro/January 2015; Aceite/Accepted - Março/March 2015 
Correspondência:

Dr. ${ }^{a}$ Ana Brasileiro

Serviço de Dermatologia e Venereologia - Hospital dos Capuchos - CHLC

Alameda S. António dos Capuchos

1169-050 - Lisboa, Portugal

Tel.: +351213136300 - Fax 213562208

Email: afmbrasileiro@gmail.com

\section{INTRODUÇÃO}

A dermite de contacto alérgica (DCA), em termos fisiopatológicos, é composta por duas fases. Na primeira - de indução ou aferente - ocorre a sensibilização ao alergénio, da qual resultam células T memória (Fig. 1A).

Quando um indivíduo sensibilizado contacta novamente com o alergénio implicado, este provoca a libertação de citocinas pelos queratinócitos e células dendríticas da epiderme, que activam moléculas de adesão nas células endoteliais atraindo leucócitos e células T efectoras. Estas últimas induzem a libertação de outras citocinas, activando mecanismos inflamatórios e levando às manifestações da dermite de contacto, o que constitui a segunda fase, de elicitação ou eferente ${ }^{1}$ (Fig. 1B).

As provas epicutâneas (PE) são o exame complementar de diagnóstico de eleição para avaliação de suspeita de DCA.' Funcionam como um teste de provocação biológica ${ }^{2}$ que avalia a possibilidade de existência de uma resposta eferente, traduzindo sensibilização ao alergénio desencadeador. A

\section{A}

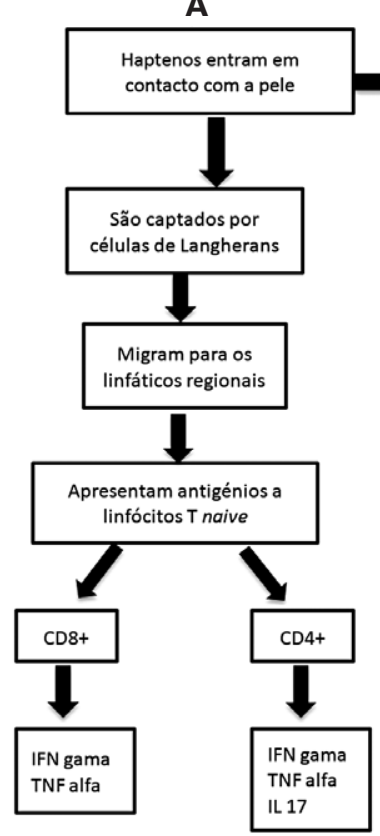

integridade da vida eferente é, portanto, de extrema importância para a sua validade enquanto meio complementar de diagnóstico.

Assim, as PE devem, idealmente, ser realizadas sem que o doente se encontre sob terapêutica imunossupressora sistémica. Contudo, existem situações na prática clínica em que, pela doença de base, esta terapêutica não pode ser suspensa, e outras em que a imunossupressão é mesmo necessária para redução da inflamação cutânea, permitindo realizar adequadamente as PE.'

Nestes casos, perante a necessidade de identificação de alergénios implicados, pode ser tentada a realização de testes epicutâneos sob imunossupressão. No entanto, a utilidade das PE nestes doentes é incerta, uma vez que a sua acuidade poderá ser afectada pelo impacto desses fármacos na resposta imunológica. ${ }^{3}$ Por outro lado, nalguns doentes em que é necessário usar imunossupressores sistémicos para que haja superfície cutânea para realizar os testes, pode ser difícil interpretar reacções fracas, dado que poderão

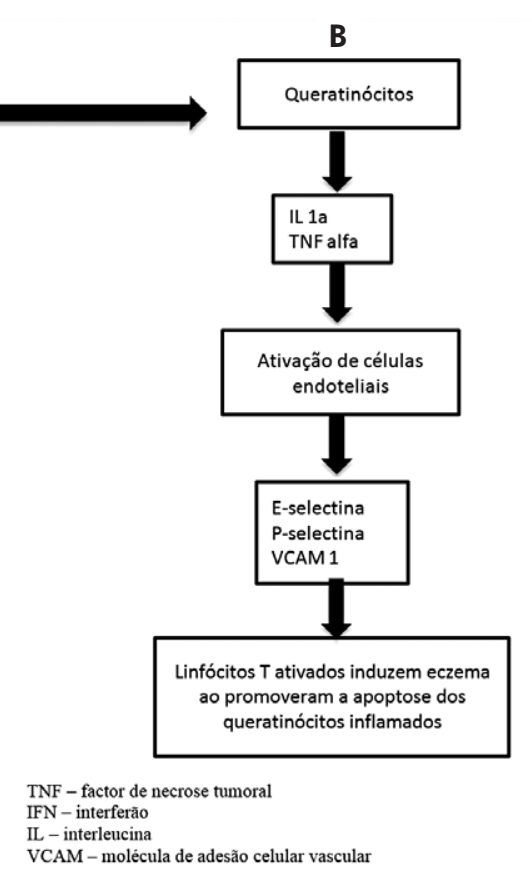

Fig 1 - A) Via aferente ou de indução de sensibilização a alergénio; B) Via eferente ou de elicitação de resposta imunológica desencadeada pelo contacto com alergénio. 


\section{GPDEC}

representar verdadeiros positivos ou corresponder a extensão da dermatite de base. ${ }^{1}$

Quando ponderamos realizar PE sob imunossupressor, importa ter em conta que há diferenças na forma como cada fármaco afecta o equilíbrio da resposta imunitária a um alergénio ${ }^{4}$, pelo que a análise do seu mecanismo de acção poderá ter algum interesse. Por outro lado, a sua dose é também um factor a considerar, dado que doses baixas de imunossupressor poderão elevar apenas ligeiramente o limiar de resposta, não sendo suficiente para suprimi-la. Alguns autores postulam que a concentração local de alergénio nas PE é elevada o suficiente para que haja activação imunitária, permitindo a sua realização sob imunossupressão. ${ }^{3}$

Por outro lado, o tipo de hapteno determina, juntamente com outros factores, o tipo de reação imunológica que é iniciada $^{5}$, podendo cada alergénio desencadear inflamação por diferentes vias. Por exemplo, foi demonstrado que o níquel estimula a produção de interleucina (IL) 4 e 56,7, esta última correlacionando-se com a intensidade da resposta; a metilcloroisotiazolinona/metilisotiazolinona (MCl/MI) de IL-2, 4, 5 e 13 ${ }^{8}$, e o crómio de interferão (IFN)-gama, IL-2, 5, 12 e 13, esta última em maior quantidade. ${ }^{9}$

presente trabalho tem como objectivo identificar os casos publicados na literatura em que foram realizados testes epicutâneos sob imunossupressão farmacológica sistémica e analisar quais os imunossupressores e em que dose permitiram a elicitação de DCA.

Consideramos que esta é uma questão com utilidade prática que possivelmente surgirá com mais frequência no futuro, dado o uso crescente de imunossupressores. ${ }^{1}$

\section{MÉTODOS}

Foi efectuada uma pesquisa bibliográfica na Medline, cruzando os termos "allergic contact dermatitis", "patch test", "imunosuppressants", "prednisone", "azathioprine", "methotrexate", "mycophenolate mofetil", "anti-TNF", "biologics". Destes, foram selecionados os artigos relevantes para o tema, tendo sido efectuada revisão das referências bibliográficas dos mesmos e sido adicionalmente incluídos os artigos considerados pertinentes.

Tabela 1 - Resumo dos estudos publicados na literatura em que foram realizadas PE sob corticoide oral.

\begin{tabular}{|c|c|c|c|c|c|c|}
\hline Ref. & $\begin{array}{l}\text { No de } \\
\text { doen- } \\
\text { tes }\end{array}$ & $\begin{array}{l}\text { Tipologia do } \\
\text { estudo }\end{array}$ & $\begin{array}{l}\text { Motivo para } \\
\text { realização } \\
\text { das PE }\end{array}$ & $\begin{array}{l}\text { Dose diária de } \\
\text { prednisolona }\end{array}$ & Resultados & $\begin{array}{c}\text { Alergénios identificados, intensidade da reação } \\
\text { e relevância ( }(\mathrm{R})\end{array}$ \\
\hline 1 & 6 & Retrospectivo & $\begin{array}{l}\text { Investigação } \\
\text { de DCA }\end{array}$ & $\begin{array}{l}5 \text { doentes sob } \\
\quad 10 \mathrm{mg} \\
1 \text { doente sob } 5 \mathrm{mg}\end{array}$ & $\begin{array}{c}100 \% \\
\text { com pelo } \\
\text { menos uma } \\
\text { sensibilização } \\
\text { identificada }\end{array}$ & $\begin{array}{l}\text { 1. Myroxylon pereirae }+++(\mathrm{R} \text { atual) } \\
\text { 2. Parafenilenodiamina (PPDA) }++ \text { e disperso laranja }++(\mathrm{R} \text { atual) } \\
\text { 3. Formaldeído }++ \text {, grotan } \mathrm{BK}++ \text {, cloreto de benzalcónio }++(\mathrm{R} \text { atual) } \\
\text { 4. Benzofenona- } 4+\text {, grotan } \mathrm{BK}+\text {, cocamida } \mathrm{DEA}+\text {, cocamidopropil } \\
\text { betaína }+ \text {, oleamidopropil dimetilamina }+ \text {, preto reactivo } 5+\text {, resi- } \\
\text { nas libertadoras de formaldeído }+ \\
\text { 5. Mistura de perfumes? }+ \text {; Metilmetacrilato ? }+(\mathrm{R} \text { atual) } \\
\text { 6. Metildibromoglutaronitrilo }+ \text {, oleamidopropil dimetilamina }+ \text {, mistura } \\
\text { de carbamatos }+ \text {, dicromato de potássio }+, M \text {. pereirae }+ \text {, sulfato } \\
\text { de níquel }+ \text { (sob } 5 \mathrm{mg} / \text { dia) (R incerta) }\end{array}$ \\
\hline 2 & 24 & $\begin{array}{l}\text { Prospectivo } \\
\text { Realizadas } \\
\text { PE em } \\
\text { doentes com } \\
\text { positividade } \\
\text { para o sulfato } \\
\text { de níquel } \\
\text { previamente } \\
\text { documentada }\end{array}$ & $\begin{array}{l}\text { Avaliação da } \\
\text { manutenção } \\
\text { ou supressão } \\
\text { da resposta } \\
\text { sob corticoide } \\
\text { oral }\end{array}$ & $\begin{array}{l}20 \text { mg com início } 2 \\
\text { dias antes das } \mathrm{PE} \text {, } \\
\text { mantendo durante } \\
\quad 10 \text { dias }\end{array}$ & $\begin{array}{l}\text { Diminuição } \\
\text { do número de } \\
\text { reações em } \\
90,5 \% \\
\text { (19 em 21) }\end{array}$ & Sulfato de níquel \\
\hline 10 & 1 & Relato de caso & $\begin{array}{l}\text { Dermatose } \\
\text { aguda } \\
\text { generalizada }\end{array}$ & $10 \mathrm{mg}$ & $\begin{array}{l}17 \text { alergénios } \\
\text { identificados, } \\
\text { foi encontrada } \\
\text { relevância } \\
\text { atual para } 9 \\
\text { deles }\end{array}$ & 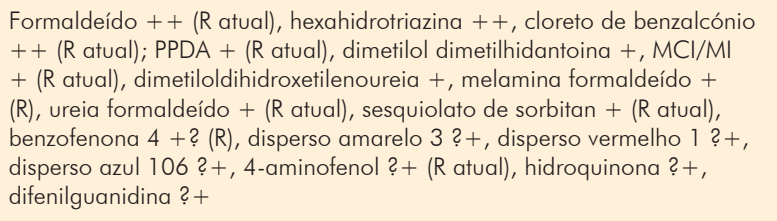 \\
\hline 12 & 43 & $\begin{array}{l}\text { Prospectivo } \\
\text { Realizadas PE } \\
\text { sob corticóide } \\
\text { sistémico em } \\
\text { doentes com } \\
\text { sensibilização } \\
\text { conhecida }\end{array}$ & $\begin{array}{c}\text { Avaliar a } \\
\text { manutenção } \\
\text { ou supressão } \\
\text { de resposta } \\
\text { sob corticóide }\end{array}$ & $\begin{array}{l}16 \text { doentes }-20 \mathrm{mg} \\
18 \text { doentes }-30 \mathrm{mg} \\
12 \text { doentes }-40 \mathrm{mg} \\
\text { iniciado } 48 \mathrm{~h} \text { antes } \\
\text { das PE e mantido } \\
\text { durante as mesmas }\end{array}$ & $\begin{array}{l}\text { A proporção } \\
\text { de reações } \\
\text { suprimidas } \\
\text { aumentou de } \\
\text { forma dose- } \\
\text { dependente }\end{array}$ & $\begin{array}{l}\text { Dos } 16 \text { sob } 20 \mathrm{mg} \text { - } 15(94 \%) \text { tiveram alguma resposta } \\
\text { Dos } 12 \text { sob } 40 \mathrm{mg} \text { - em } 3(25 \%) \text { houve supressão completa da resposta, } \\
\text { em } 8(66 \%) \text { diminuiu e manteve-se num doente }\end{array}$ \\
\hline
\end{tabular}




\section{GPDEC}

\section{RESULTADOS}

1. Corticóides

Os corticóides suprimem a activação das células dendríticas imaturas, a ativação das células $T$ e a sua função estimuladora através da diminuição da produção de IL-2, 4, 6, 20, factor de necrose tumoral (TNF)-alfa, factor estimulador das colónias de granulócito-macrófago e IFN-gama. ${ }^{10,11}$

Existem na literatura vários casos publicados de PE sob corticóide sistémico, os quais se encontram sumarizados na Tabela 1.

No total, foram testados 77 doentes sob corticóide sistémico, com doses variando entre 5 e 40mg/dia. Nos indivíduos sob prednisolona 5 a 10mg, não parece ter havido alterações da resposta de hipersensibilidade cutânea ${ }^{1,10}$, embora o número de casos seja reduzido e os testes não tenham sido posteriormente repetidos sem imunossupressão concomitante. Anveden et a ${ }^{2}$ realizaram PE sob prednisolona $20 \mathrm{mg} /$ dia em 24 doentes com sensibilização conhecida ao sulfato de níquel, tendo verificado que houve uma diminuição do número de respostas que anteriormente tinham sido extremamente positivas. Contudo, as observações de Feuermen e colaboradores ${ }^{12}$ suportam a sua conclusão de que até $20 \mathrm{mg} /$ dia não há alteração significativa do resultado das PE. Para doses superiores, parece ser consensual que há um risco significativo de falsos negativos; talvez por isso as PE tenham sido realizadas sob doses inferiores de corticóide nos estudos mais recentes. ${ }^{12}$

\section{Ciclosporina $\mathrm{A}(\mathrm{CyA})$}

A CyA diminui a produção de IL-2 e 8, suprimindo consequentemente a ativação de linfócitos $T$ e neutrófilos, respectivamente. ${ }^{13,14}$ Diminui também a libertação de histamina pelos mastócitos e a migração de linfócitos T CD8+ para a pele. ${ }^{14}$

$\mathrm{Na}$ Tabela 2 encontram-se sumarizados os 6 estudos ${ }^{1,13,15-18}$ em que foram realizadas provas epicutâneas em doentes sob CyA.

Tabela 2 - Sumarização dos dados da literatura relativos à realização de PE sob CyA.

\begin{tabular}{|c|c|c|c|c|c|c|}
\hline Ref. & $\begin{array}{l}N^{\circ} \text { de } \\
\text { doen- } \\
\text { tes }\end{array}$ & $\begin{array}{l}\text { Tipologia do } \\
\text { estudo }\end{array}$ & $\begin{array}{l}\text { Motivo para } \\
\text { realização } \\
\text { das PE }\end{array}$ & $\begin{array}{l}\text { Dose de; sob } \\
\text { terapêutica à data de } \\
\text { realização dos testes? }\end{array}$ & Resultados & $\begin{array}{c}\text { Alergénios identificados, intensidade } \\
\text { da reação e relevância ( } R \text { ) }\end{array}$ \\
\hline 1 & 2 & Retrospectivo & & $\begin{array}{l}200 \text { e } 300 \mathrm{mg} / \mathrm{dia} \\
\text { respectivamente }\end{array}$ & 100 & Cloreto de cobalto +++ , álcool cinâmico ++ \\
\hline 13 & 12 & $\begin{array}{l}\text { Prospectivo, todos } \\
\text { os doentes sob CyA } \\
\text { há }>1 \text { mês }\end{array}$ & $\begin{array}{l}\text { Investigação de } \\
\text { dermatose }\end{array}$ & & $\begin{array}{l}\text { Negativo em } 6 \text { doentes } \\
(50 \%)\end{array}$ & $\begin{array}{ll}\text { 1. } & \text { Mistura perfumes } \|++ \text {, citronelol }+ \\
\text { (R incerta) } \\
\text { 2. Mistura tiurans }++ \text {, propil galato }+++ \text {, } \\
\text { dissulfeto tetrametiltiuram }+ \text {, cosmético } \\
\text { próprio }+(\mathrm{R} \text { atual) } \\
\text { 3. Sulfato de níquel }+(\mathrm{R} \text { incerta) } \\
\text { 4. Colofónia }+++(\mathrm{R} \text { atual }) \\
\text { 5. Sulfato de níquel }+(\mathrm{R} \text { passada }) \\
\text { 6. Neomicina }+(\mathrm{R} \text { passada) }\end{array}$ \\
\hline 15 & 10 & $\begin{array}{l}\text { Prospectivo; em } \\
\text { doentes com "angry } \\
\text { back", repetição } \\
\text { das PE sob CyA }\end{array}$ & $\begin{array}{l}\text { Avaliar o efeito } \\
\text { da CyA na } \\
\text { realização de PE } \\
\text { em doentes com } \\
\text { DCA e "angry } \\
\text { back" }\end{array}$ & $\begin{array}{l}5 \mathrm{mg} / \mathrm{Kg} / \text { dia, } 3 \text { dias } \\
\text { consecutivos }\end{array}$ & $\begin{array}{l}56 \% \text { das reacções } \\
\text { desapareceram, enquanto } \\
\text { que as que permaneceram } \\
\text { positivas foram as que } \\
\text { tinham relevância no } \\
\text { contexto de cada doente }\end{array}$ & \\
\hline 16 & 6 & $\begin{array}{l}\text { Prospectivo; PE } \\
\text { realizadas antes e } \\
2 \text { semanas após o } \\
\text { início de CyA }\end{array}$ & $\begin{array}{l}\text { Estudar os } \\
\text { efeitos da CyA } \\
\text { na DCA }\end{array}$ & $5 \mathrm{mg} / \mathrm{Kg} / \mathrm{dia}$ & $\begin{array}{l}\text { As reações verdadeiras } \\
\text { positivas não foram } \\
\text { afectadas pela CyA, só } \\
\text { as fracas e duvidosas. } \\
\text { CyA inibe a resposta a } \\
\text { certos alergénios em } \\
\text { concentrações baixas. }\end{array}$ & $\begin{array}{l}\text { Alergénios testados: sulfato de níquel, crómio, } \\
\text { cloreto de cobalto, mistura de tiurans, } \\
\text { mercaptobenzotiazol }\end{array}$ \\
\hline 17 & 15 & $\begin{array}{l}\text { Prospectivo; testes } \\
\text { realizados sob CyA } \\
\text { e repetidos } 1 \text { mês } \\
\text { após o início do } \\
\text { tratamento }\end{array}$ & $\begin{array}{l}\text { Estudar os } \\
\text { efeitos da CyA } \\
\text { na DCA }\end{array}$ & $\begin{array}{l}5 \mathrm{mg} / \mathrm{kg} / \text { dia durante } 4 \\
\text { semanas e depois } 3 \mathrm{mg} / \\
\mathrm{Kg} / \text { dia }\end{array}$ & $\begin{array}{l}\text { As reações fortes a extremas } \\
\text { mantiveram-se, enquanto } \\
\text { que as respostas fracas ( }+ \text { ) } \\
\text { se tornaram negativas }\end{array}$ & \\
\hline 18 & 33 & $\begin{array}{l}\text { Prospectivo; testes } \\
\text { realizados antes } \\
\text { do início de CyA } \\
\text { e repetidos } 1 \text { mês } \\
\text { após o tratamento } \\
\text { com CyA }\end{array}$ & $\begin{array}{l}\text { Investigação de } \\
\text { dermatose }\end{array}$ & $\begin{array}{c}5 \mathrm{mg} / \mathrm{Kg} / \text { dia durante } 10 \\
15 \text { dias }\end{array}$ & $\begin{array}{l}\text { As reações fracamente } \\
\text { positivas foram inibidas, } \\
\text { mantendo-se as fortes }(++) \\
\text { e as extremas }(+++)\end{array}$ & \\
\hline
\end{tabular}


No total, foram testados 78 doentes. Na maioria dos estudos (referentes a 64 doentes) as provas foram realizadas sem qualquer imunossupressão e foram depois repetidas enquanto os doentes se encontravam sob CyA. Todos estes estudos concluíram que as reaç̧ões alérgicas fortes ou extremas não foram afectadas pela terapêutica com CyA, podendo apenas ocorrer uma ligeira diminuição da intensidade do eritema. Por outro lado, este fármaco parece inibir as reacções fracas ou duvidosas, as quais têm maior probabilidade de corresponder a reacções irritativas, representando falsos negativos. Desta forma, a terapêutica com CyA parece aumentar o limiar a partir do qual a reacção alérgica ocorre.

\section{Azatioprina}

A azatioprina diminui a síntese de ácidos nucleicos, o número de células de Langerhans e a função das células T. ${ }^{19}$

Existem poucos casos de realização de PE em doentes sob Azatioprina. Na única série publicada, foram testados 5 doentes (2 sob Azatioprina $50 \mathrm{mg} /$ dia, 2 sob $150 \mathrm{mg} /$ dia e um sob $200 \mathrm{mg} / \mathrm{dia})$. Foi identificado apenas um resultado positivo (cloreto de cobalto + ) num doente que se encontrava sob $50 \mathrm{mg} /$ dia. $^{13}$

Pigatto e colaboradores descreveram um caso em que foi suspensa a terapêutica com azatioprina $(100 \mathrm{mg} / \mathrm{dia}) 2$ dias antes da realização das $\mathrm{PE}$, tendo sido observada reacção $(++)$ ao sulfato de níquel $5 \% .{ }^{20}$

O número diminuto de casos não permite extrapolar os achados, embora se verfique que, aparentemente, a azatioprina em doses de $50-100 \mathrm{mg} /$ dia possa permitir a elicitação de DCA nalguns doentes.
4. Metotrexato (MTX)

O MTX inibe a síntese de DNA, inibe a secreção de IL-1, 10, TNF alfa e promove a apoptose dos linfócitos CD4+ ativados. ${ }^{21}$

No total dos 10 casos descritos na literatura ${ }^{3,13}$ (Tabela 3) em que foram efetuadas PE em doentes medicados com MTX (dose variando entre $5-25 \mathrm{mg} / \mathrm{semana}$ ), foi identificada pelo menos uma positividade em 6 deles (60\%). Destes, 3 encontravam-se sob MTX em dose baixa $(5-7.5 \mathrm{mg} / \mathrm{semana})$.

Para doses superiores de MTX, os 4 (em 7) doentes com positividades tinham suspenso MTX na semana das PE. Talvez a suspensão do fármaco seja necessário para que ocorra resposta para doses de $15 \mathrm{mg}$ semanais ou superiores; contudo, o número reduzido de casos e a ausência de aleatoriedade nos estudos não permite estabelecer uma relação significativa.

\section{Micofenolato de mofetil (MMF)}

O MMF inibe a proliferação de linfócitos $T$, bem como a maturação e expressão de citocinas por parte das células dendríticas. ${ }^{22}$

Existem apenas 4 casos publicados referentes a realização de PE sob MMF, $, 3,13$ tendo as provas sido positivas num doente, que se encontrava sob MMF $2 \mathrm{~g} /$ dia. Foi identificada sensibilização a cloreto de cobalto + , ouro + e trietanolamina + , cuja relevância foi considerada passada. Contudo, perante a manutenção de queixas e da suspeição de DCA, as PE foram repetidas 14 meses depois, já sem MMF. Nesta data, verificou-se positividade para formaldeído $(++)$, agentes libertadores de formaldeído (+) e MCl/MI (++), com resolução da dermatose mediante a evicção de produtos contendo estes conservantes. ${ }^{1}$

Tabela 3 - Resumo dos estudos publicados na literatura em que foram realizadas PE sob MTX.

\begin{tabular}{|c|c|c|c|}
\hline Ref. & Dose MTX & Suspendeu MTX para realizar PE? & Alergénios identificados, intensidade da reação e relevância (R) \\
\hline 3 & $30 \mathrm{mg} / \mathrm{sem}$ & Não & Negativo \\
\hline 3 & $25 \mathrm{mg} / \mathrm{sem}$ & Sim, na semana das PE & M. pereirae?+, ácido benzóico? + (R atual) \\
\hline 3 & $20 \mathrm{mg} / \mathrm{sem}$ & Não & Negativo \\
\hline 3 & $20 \mathrm{mg} / \mathrm{sem}$ & Sim, na semana das PE & Negativo \\
\hline 13 & $15 \mathrm{mg} / \mathrm{sem}$ & Não & Negativo \\
\hline 3 & $15 \mathrm{mg} / \mathrm{sem}$ & Sim, na semana das PE & Formaldeído,$+ \mathrm{MCl} / \mathrm{MI}++(\mathrm{R}$ atual $)$ \\
\hline 3 & $15 \mathrm{mg} / \mathrm{sem}$ & Sim, na semana das PE & Ácido benzóico ++ , cloreło de cobalto ++ (R atual) \\
\hline 3 & $7.5 \mathrm{mg} / \mathrm{sem}$ & Não & $\begin{array}{c}\text { Bacitracina }+++ \text {, neomicina }+++ \text {, sulfato de níquel }+++ \text {, formaldeído e resinas } \\
\text { libertadoras de formaldeído }(+/++) \text { (R atual) }\end{array}$ \\
\hline 13 & $5-7.5 \mathrm{mg} / \mathrm{sem}$ & Não & Sulfato de níquel + , dicromato de potássio + , mistura de perfumes $I++$ (R passada) \\
\hline 13 & $5 \mathrm{mg} / \mathrm{sem}$ & Não & M. pereirae + ( $\mathrm{R}$ incerta $)$ \\
\hline
\end{tabular}




\section{GPDEC}

Contudo o intervalo de 14 meses entre as provas não pode excluir que a sensibilizaçãoo tenha ocorrido então.

Dos 3 doentes com testes negativos, 1 encontrava-se sob MMF $1 \mathrm{~g} /$ dia $^{3}$ e 2 sob $2 \mathrm{~g} /$ dia. $^{13} \mathrm{O}$ reduzido número de casos descritos na literatura, não permite que se estabeleçam conclusões acerca do efeito do MMF e da sua dosagem no resultado das PE.

\section{Fármacos biológicos}

Teoricamente, o TNF alfa está envolvido em mecanismos de hipersensibilidade retardada, pelo que os seus inibidores podem suprimir a DCA. ${ }^{1}$ No total, existem 11 casos reportados de realização de PE sob um dos inibidores do TNF alfa:

\subsection{Infliximab}

Estão publicados 3 casos de doentes que efectuaram PE sob infliximab, que se encontram resumidos na Tabela 4. Todos estes doentes tiveram várias positividades, o que sugere que o infliximab não inibe, pelo menos por completo, a resposta imunológica subjacente à elicitação de DCA.

Tabela 4 - Resumo da informação disponível na literatura quanto à realização de PE em doentes sob fármacos biológicos.

\begin{tabular}{|c|c|c|c|c|}
\hline $\begin{array}{l}\text { Fármaco } \\
\text { biológico }\end{array}$ & Ref. & Dose & $\begin{array}{l}\text { Tempo desde última } \\
\text { administração de biológico }\end{array}$ & Alergénios identificados, intensidade da reação e relevância ( $R$ ) \\
\hline \multirow{3}{*}{ Infliximab } & 1 & Desconhecida & Desconhecida & $\begin{array}{l}\text { Mistura de carbamatos, mistura de tiurans, tetraetiltiuram dissulfido, PPDA, dietilditio- } \\
\text { carbamato }\end{array}$ \\
\hline & 4 & Desconhecida & 2 semanas & $\begin{array}{l}\text { Benzofenona- } 3+\text {, cloreto de cobalto }+ \text {, tiosulfato de sódio }++ \text {, bacitracina }++ \text {, } \\
\text { álcoois da lanolina }++ \text {, mistura de carbamatos }+++ \text {, mistura de tiurans }++ \text {, formal- } \\
\text { deído }++ \text {, etilenodiamina }+ \text {, dicromato de potássio }+ \text {, sulfato de níquel }++ \text {, mistura } \\
\text { de parabenos }+ \text {, mistura de perfumes } 1+\text {, cloreto de benzalconio, hidroxitolveno } \\
\text { butilado }+\end{array}$ \\
\hline & 19 & $\begin{array}{l}5 \mathrm{mg} / \mathrm{Kg} \mathrm{a} \\
\text { cada } 7 \mathrm{sem}\end{array}$ & 3 semanas & $\begin{array}{l}\text { Mistura de tiurans }+++ \text {, mistura de carbamatos }+++ \text {, PPDA }+++ \text {, tetrametiltiuram } \\
\text { disulfido }+++ \text {, tetrametiltiuram monosulfido }+++ \text {, dipentametilenotiuram dissulfido } \\
++ \text {, dietilcarbamato de zindo }++ \text {, álcoois da lanolina }++ \text {, bacitracina }++ \text {, sulfato de } \\
\text { níquel }++ \text {, formaldeído }++ \text {, etilenodiamina dihidroclorido }++ \text {, mistura de parabenos } \\
+ \text {, mistura de perfumes }+ \text {, cloreto de benzalcónio }+ \text {, benzofenona-3 }+ \text {, neomicina }+ \text {, } \\
\text { dicromato de potássio }+ \text {, cloreto de cobalto }+ \text {, diazolidinil ureia }+ \text {, DMDM hidantoina } \\
+ \text {, imidazolidinil ureia }+ \text {, BIOBAN CS-1246 }+ \text {, BIOBAN CS- } 1135+\text {. (R) }\end{array}$ \\
\hline \multirow{4}{*}{ Etanercept } & \multirow{4}{*}{4} & \multirow{4}{*}{ Desconhecida } & 5 dias & Negativo \\
\hline & & & 7 dias & Negativo \\
\hline & & & 6 dias & $\begin{array}{l}\text { Sulfato de níquel }+ \text {, mistura de parabenos }+ \text {, abitol }+ \text {, tiossulfato de sódio }+ \text {, olcami- } \\
\text { dopropil dimetilamina }+ \text {. }\end{array}$ \\
\hline & & & 8 dias & Sulfato de neomicina ++ , quaternium $15+$, M. pereirae ++ , bacitracina +++ \\
\hline \multirow{4}{*}{ Adalimumab } & 4 & \multirow{3}{*}{ Desconhecida } & 2 dias & $\mathrm{MCl} / \mathrm{MI}+$, ouro ++ , cloreto de benzalcónio + , euxyl K400 +. \\
\hline & 4 & & 6 dias & $\begin{array}{l}\text { M. pereirae }++ \text {, glutaraldeido }+ \text {, cloreto de cobalto }++ \text {, tiossulfato de sódio }++ \text {, di- } \\
\text { tiodimorfolona }+ \text {, amidoamina }+ \text {, cloreto de benzalcónio }+ \text {, metildibromoglutaronitrilo } \\
++ \text {, monoleato de sorbitan }+ \text {, cocamidopropil betaína }+ \text {, laurel-glucosido }+\end{array}$ \\
\hline & 4 & & 8 dias & Negativo \\
\hline & 13 & $40 \mathrm{mg} / \mathrm{sem}$ & Desconhecida & Sulfato de níquel $+(R$ indeterminada $)$ \\
\hline \multirow{7}{*}{ Ustecinumab } & \multirow{7}{*}{4} & \multirow{7}{*}{ Desconhecida } & 28 dias & Tiossulfato de sódio ++ \\
\hline & & & 37 dias & $\begin{array}{l}\text { Alcoóis da lanolina }++ \text {, } M \text {. pereirae }++ \text {, sulfato de níquel }+++, \mathrm{MCl} / \mathrm{MI}++ \text {, mis- } \\
\text { tura de perfumes } \|+ \text {, iodopropinil butilcarbamato }++\end{array}$ \\
\hline & & & 28 dias & M. pereirae ++ , Propileno glicol + \\
\hline & & & 112 dias & Sulfato de níquel ++ , bacitracina + \\
\hline & & & 42 dias & $\begin{array}{l}\text { Benzofenona- } 4+\text {, bacitracina }+ \text {, mistura de perfumes } \|+ \text {, mistura de perfumes } \mathrm{I}+\text {, } \\
\text { cloreto de benzalcónio }+ \text {, amercol L101 }+ \text {, propilenoglicol }+\end{array}$ \\
\hline & & & 238 dias & Neomicina + , etilenodiamina ++ \\
\hline & & & 28 dias & $\begin{array}{l}\text { Formaldeído }++ \text {, quaternium } 15+++ \text {, } M \text {. pereirae }+,++, \mathrm{MCl} / \mathrm{MI}++ \text {, mistura de } \\
\text { perfumes } \mathrm{II}++\end{array}$ \\
\hline
\end{tabular}




\subsection{Etanercept}

Estão descritos 4 casos de doentes testados com PE enquanto medicados com etanercept, dos quais 2 tiveram provas negativas e nos outros 2 foram identificadas várias sensibilizações (Tabela 4).

\subsection{Adalimumab}

Existem 4 casos na literatura de realização de provas epicutâneas em doentes medicados com adalimumab. Nestes, foi identificada pelo menos uma sensibilização em 3, conforme se pode observar na Tabela 4.

Os 3 doentes sob infliximab tiveram mais do que uma positividade identificada. $\bigcirc$ mesmo se verificou 2 em 4 dos doentes sob etarnecept e 3 em 4 dos doentes sob adalimumab.

No global, a maioria dos doentes sob anti-TNF alfa tiveram pelo menos uma sensibilização identificada, o que sugere que os inibidores do TNF alfa não inibem a resposta imunológica subjacente à elicitação de DCA. Contudo, o efeito exacto do bloqueio anti-TNF alfa na hipersensibilidade retardada permanece desconhecido. ${ }^{23} \mathrm{O}$ número de casos descritos é demasiado pequeno para validar qualquer comparação entre os diversos anti-TNF alfa.

Existem também dados disponíveis relativos ao ustecinumab, um inibidor da via IL-12/IL-23.

\subsection{Ustecinumab}

Estão descritos 7 casos $^{4}$ de PE em doentes sob este inibidor da via IL-12/23, tendo sido identificadas positividades em todos eles (Tabela 4).

Adicionalmente, existe um caso descrito em que a doente encontrava-se sob MTX (15mg/semana) e houve positividade para hidroxizina +++ , o que foi considerado relevante dado que a doente tinha história prévia de exantema maculo-papular à hidroxizina. Posteriormente, a mesma doente iniciou ustecinumab $45 \mathrm{mg}$ na semana 0,4 e depois a cada 12 semanas, mantendo o MTX na mesma dose. Foram repetidas PE após o início e às 12 semanas de terapêutica com ustecinumab, com os mesmos resultados em ambas as avaliações. ${ }^{24}$

Em todos os doentes sob ustecinumab testados foi possível demonstrar sensibilização a pelo menos um alergénio, o que significa que a inibição da via IL-12/IL-23 não bloqueia, pelo menos na totalidade, a expressão da hipersensibilidade do tipo IV.

Kim e colaboradores ${ }^{4}$ compararam o resultado dos testes obtidos em 15 doentes com psoríase sob agentes biológicos (tanto anti-TNF alfa como anti-IL12/23) com os de 16 doentes com psoríase tratados com terapias clássicas (dos quais 4 se encontravam sob imunossupressor sistémico), e concluíram não haver diferença significativa na prevalência de testes positivos entre os 2 grupos.
Em termos práticos, é necessário que decorram pelo menos 5 semi-vidas para que se considere que o doente não está sob o efeito do fármaco. Em todos estes doentes, a última administração do fármaco biológico distou o tempo correspondente a 2 semi-vidas da realização das $\mathrm{PE}$, pelo que havia ainda fármaco em circulação. Assim, os autores sugerem que o facto de o doente se encontrar sob agente biotecnológico não deve ser uma contraindicação para realização de $\mathrm{PE}{ }^{4}$

\section{Associação de imunossupressores}

Existem 15 casos descritos em que foram realizadas PE em doentes sob associação de 2 imunossupressores sistémicos (Tabela 5). A análise destes resultados não é linear, dada a heterogeneidade de associações farmacológicas e de doses. Contudo, verifica-se que dos 8 doentes em que as PE foram negativas, 6 se encontravam sob azatioprina, enquanto que dos 7 indivíduos com testes positivos, apenas um se encontrava medicado com este fármaco. Tal poderá ser indicativo de um papel supressor de resposta alérgica por parte da azatioprina, ou poderá resultar da supressão combinada de várias vias, decorrente da associação de outro imunossupressor. 0 reduzido número de casos não permite, mais uma vez, estabelecer conclusões fundamentadas.

\section{DISCUSSÃO}

A imunossupressão é utilizada com frequência crescente em pacientes transplantados ou no tratamento de doenças inflamatórias, de etiologia alérgica ou auto-imune. ${ }^{1}$ De facto, por vezes é prescrita pelo próprio dermatologista para controlo de um eczema em generalização, cuja investigação poderá tornar relevante a avaliação do doente através de PE.

Assim, vários autores reportaram a realização de PE sob diversos imunossupressores, em monoterapia ou associação. Contudo, trata-se de estudos heterogéneos, com reduzido número de doentes, o que limita as conclusões da sensibilidade das PE sob cada imunossupressor nas suas várias dosagens.

O conhecimento mais detalhado do modo de acção de cada imunossupressor, das vias inflamatórias envolvidas na DCA e das vias estimuladas preferencialmente por cada alergénio aquando da elicitação de resposta imunológica, poderão a ajudar a prever que reacções podem ser supressas por cada fármaco.

Por exemplo, a ciclosporina inibe a IL-8 e a activação dos neutrófilos, que são responsáveis pela formação de pústulas, as quais estão associadas a reacções do tipo irritativo. Este mecanismo explica os resultados de Vena e colaboradores, ${ }^{15}$ que mostraram que a $\mathrm{CyA}$ inibe as reacções fracas, do tipo irritativo; não inibindo contudo as reacções de maior intensidade, do tipo alérgico, o que poderá ter utilidade em 


\section{GPDEC}

Tabela 5 - Resumo dos casos reportados na literatura quanto à realização de PE em doentes sob associação de imunossupressores sistémicos.

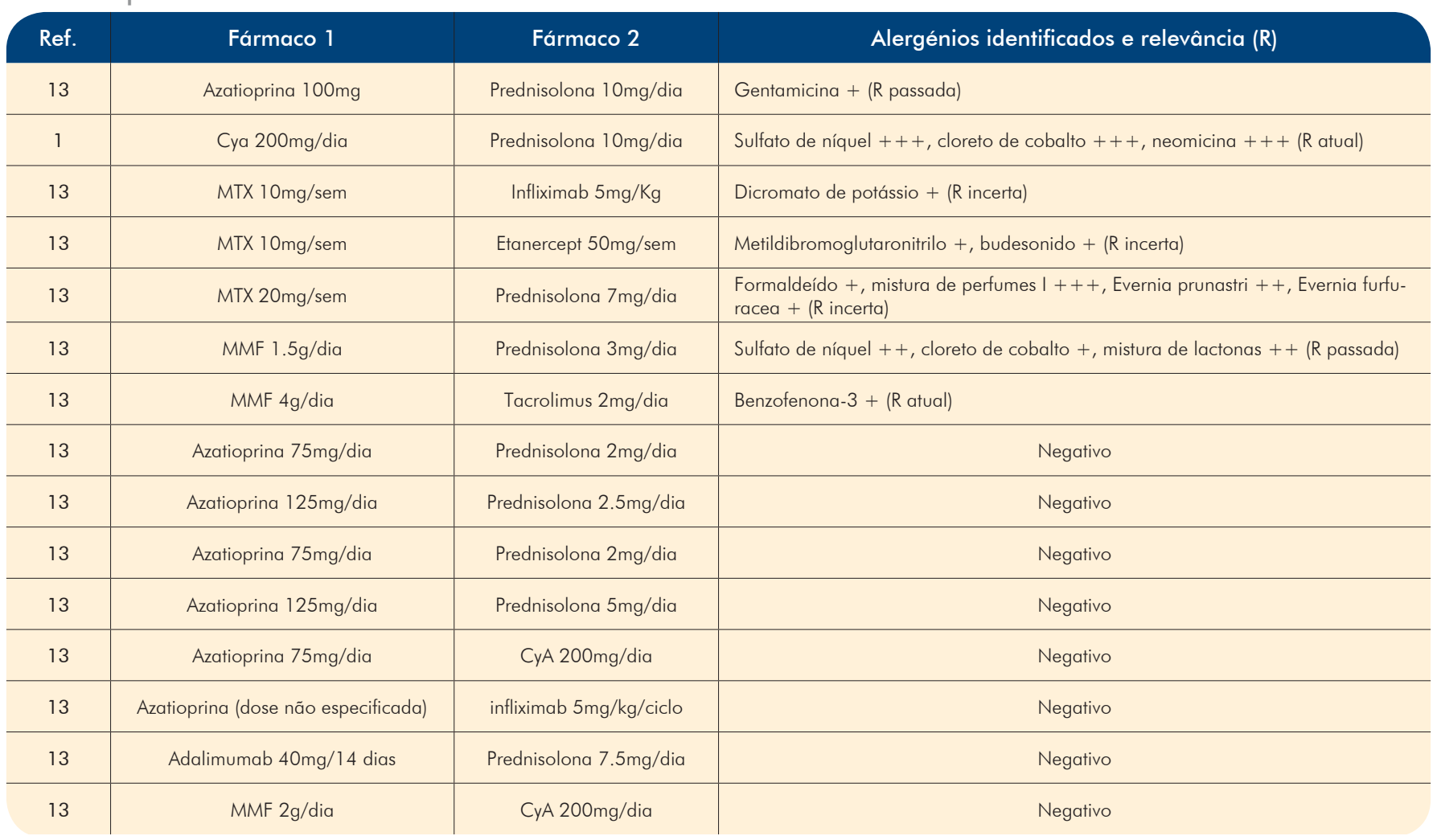

certas situações da prática clínica. De referir também que dados da literatura apontam para que a CyA afecte mais a fase de sensibilização do que a resposta de elicitação. ${ }^{16}$

Por outro lado, no que diz respeito à sensibilização para o níquel, foi demonstrado que este estimula a libertação IL-4 e 5. Os corticóides bloqueiam a expressão desta última citocina, o que poderá, pelo menos em parte, justificar que a reacção a este alergénio tenha sido inibida em $90.5 \%$ dos indivíduos sob prednisolona $20 \mathrm{mg} /$ dia. $^{2}$

Quando as PE são realizadas sob imunossupressor, é difícil apurar, nos casos com testes negativos, se estes seriam igualmente negativos sem influência do fármaco. Por outro lado, nos casos em que há positividades, poderão existir outras que não são identificadas devido à imunossupressão. Nos estudos retrospectivos e nos relatos de caso estas situações poderão não ser devidamente identificadas.

Contudo, para alguns fármacos, os testes foram realizados antes e durante a terapêutica com imunossupressores - em 64 doentes com prednisolona ${ }^{2,12}$ (resultados contraditórios), em 64 doentes com CyA (inibe as respostas irrelevantes, as relevantes mantêm-se), num doente sob MMF, em que na repetição se encontraram positividades relevantes que não se tinham objectivado nas primeiras PE (embora com intervalo de 14 meses, pelo que pode ter ocorrido sensibilização de novo) e numa doente tratada com ustecinumab $^{13}$ (obtiveram-se os mesmos resultados).

\section{CONCLUSÃO}

A terapêutica imunossupressora não deve ser uma contra-indicação absoluta para realização de $\mathrm{PE}$, , podendo ser elicitadas reacções positivas em doentes sob prednisolona, azatioprina, CyA, MTX, MMF, infliximab, etanercept, adalimumab e ustecinumab. A CyA parece inibir as respostas irritativas/irrelevantes e diminui a intensidade das reacções alérgicas, sobretudo as fracas. Dado que se mantém a possibilidade de elicitação de reacções alérgicas, a CyA poderá, provavelmente, ser utilizada em doentes com dermatoses disseminadas, cujo controlo é necessário para que haja área suficiente de superfície cutânea íntegra, onde serão colocadas as câmaras para realização das PE. Quanto aos restantes fármacos, os dados da literatura não são suficientes para obter conclusões.

Contudo, importa ter em conta a dificuldade de identificar falsos negativos, devendo as provas ser repetidas sempre que a suspeição clínica de DCA persista, se exequível sem imunossupressor ou com a dose mais baixa possível. Aguns autores 
propõem que sejam utilizadas concentrações superiores de alergénio para tentar miminizar os falsos negativos e aumentar a probabilidade de elicitar uma resposta. Outros sugerem que se devem valorizar reacções ligeiras ou duvidosas, dado a diminuição espectável da resposta inflamatória. ${ }^{3}$

Permanece por esclarecer qual o efeito exacto de cada fármaco imunossupressor nas $\mathrm{PE}$, sendo necessários mais estudos para melhor clarificar a validade e método apropriado de realização de provas naquelas circunstâncias. ${ }^{13}$

Na prática e na ausência de estudos mais concretos e perante um paciente que sobre imunossupressores desenvolve reacções de eczema em que é necessário identificar um possível alérgeno causal, as presentes guidelines da ESCD (European Society of Contact Dermatitis) recomendam realizar as PE com a dose mínima possível de imunossupressoes, com os cuidados referidos na interpretação sobretudo dos resultados duvidosos ou negativos. ${ }^{25}$

\section{BIBLIOGRAFIA}

1. Rosmarin D, Gottlieb AB, Asarch A, Scheinman PL. Patch-testing while on systemic immunosuppressants. Dermatitis. 2009; 20(5):265-70.

2. Anveden I, Lindberg $M$, Andersen KE, et al. Oral prednisone suppresses allergic but not irritant patch test reactions in individuals hypersensitive to nickel. Contact Dermatitis. 2004; 50(2):298-303.

3. Wentworth AB, Davis MDP. Patch Testing With the Standard Series When Receiving Immunosuppressive Medications. 2014:195-200.

4. Kim N, Notik S, Gottlieb AB, Scheinman PL. Patch Test Results in Psoriasis Patients on Biologics. 2014; 25(4).

5. Zollner TM, Igney FH, Asadullah K. Acute and chronic models of allergic contact dermatitis: advantages and limitations. Ernst Schering Res Found Workshop. 2005:255-75.

6. Niiyama S, Tamauchi H, Amoh $Y$, Terashima M, Matsumura Y, Kanoh M, Habu S, Komotori J KK. TH2 immune response plays a critical role in the development of nickel-induced allergic contact dermatitis. Int Arch Allergy Immunol. 2010; 153(3):303-14.

7. Czarnobilska E, Jenner B, Kaszuba-zwoinska J, Kapusta M, Obtu K, Thor P. Contact allergy to nickel: patch test score correlates with IL-5, but not with IFN-gamma nickel-specific secretion by peripheral blood lymphocytes. Ann Agric Env Med. 2009;16(1):37-41.

8. Masjedi K, Ahlborg N, Gruvberger B, Bruze M, Karlberg a. Contact Dermatitis and Allergy Methylisothiazolinones elicit increased production of both T helper ( Th ) 1 - and Th2-like cytokines by peripheral blood mononuclear cells from contact allergic individuals. 2003:1172-82.

9. Martins LE RV. Cytokine detection for the diagnosis of chromium allergy * Detecção de citocinas no diagnóstico de pacientes alérgicos ao cromo. J Eur Acad Dermatol Venereol. 2013; 88(5):719-25.

10. Olupona T, Scheinman P. Successful patch testing despite concomitant low-dose prednisone use. Dermatitis. 2007; 19:117-8.

11. Jackson S, Gilchrist H NLJ. Update on the dermatologic use of systemic glucocorticosteroids. Dermatol Ther. 2007; 20(4):187-205.

12. Feuerman $E$ LA. A study of the effect of prednisone and an antihistamine on patch test reactions. Br J Dermatol. 1972; 86:68-71.

13. Wee JS, White JM MJ et al. Patch testing in patients treated with systemic immunosuppressive agents and cytokine inhibitors. Br J Dermatol. 2010; Conference 2:165-9.

14. Madan V GC. Systemic ciclosporin and tacrolimus in dermatology. Dermatol Ther. 2007; 20:239-50.

15. Vena G a., Foti C, Piazzola L, Angelini G. Can cyclosporin $A$ help distinguish allergic from irritant patch test reactions? Contact Dermatitis. 1994; 31:256-7. doi:10.1111/i.1600-0536.1994.tb01998.x.

16. Higgins EM, McLelland J, Friedmann PS, Matthews JN SS. Oral cyclosporin inhibits the expression of contact hypersensitivity in man. J Dermatol Sci. 1991; 2(2):79-83.

17. Flori L, Perotti R, Mazzatenta C AL. Cyclosporin A in the treatment of severe allergic contact dermatitis. J Eur Acad Dermatol Venereol. 1993; 2:200-6.

18. Flori ML AL. Patch tests after cyclosporin A treatment in hyperreactive patients. Contact Dermatitis. 1994; $31(5): 325$.

19. Patel A, Swerlick R MC. Azathioprine in dermatology: the past, the present, and the future. J Am Acad Dermatol. 2006; 55:369-89.

20. Pigatto PD, Cesarani a., Barozzi S, Guzzi G. Positive response to nickel and azathioprine treatment. J Eur Acad Dermatology Venereol. 2008; 22:891.

21. Bangert C CM. Methotrexate in dermatology. Dermatol Ther. 2007; 20:216-28.

22. Zwerner J FD. Mycophenolate mofetil. Dermatol Ther. 2007; 20:229-38.

23. Rosmarin D, Bush M, Scheinman PL. Patch testing a patient with allergic contact hand dermatitis who is taking infliximab. J Am Acad Dermatol. 2008; 59:145-7.

24. Nosbaum A, Rozieres A, Balme B, Goujon C, Nicolas JF, Bérard F. Blocking $T$ helper $1 / T$ helper 17 pathways has no effect on patch testing. Contact Dermatitis. 2013; 68:58-9.

25. Johansen JD, Aalto-Korte K, Agner T, Andersen KE, Bircher A, Cannavó et al. ESCD practical guideline on diagnostic patch testing. Recommendations on best practice. Contact Dermatitis 2015 (in press). 